\title{
The application of a phosphorus nitrogen flame retardant curing agent in epoxy resin
}

https://doi.org/10.1515/epoly-2019-0058

Received May 29, 2019; accepted August 05, 2019.

\begin{abstract}
In order to improve the compatibility of flame retardant and epoxy resin, a phosphorus nitrogen flame retardant curing agent poly(p-xylylenediamine spirocyclic pentaerythritol bisphosphonate) (PPXSPB) was synthesized. FTIR, 'HNMR, and mass spectroscopy were used to identify the chemical structure of PPXSPB. Epoxy resin (E-44) and PPXSPB as the raw material, a series of thermosetting systems were prepared. The effects of PPXSPB on flame retardancy, water resistance, thermal degradation behavior, mechanical properties and the adhesive strength of EP/PPXSPB thermosets were investigated. The results show that with the increase of phosphorus content, the oxygen index and carbon residue of the system both increased significantly, and the heat release rate gradually decreased, which is of great significance in delaying the occurrence of fire. When the phosphorus content is 3.24\% in EP/PPXSPB thermosets, EP-2 can successfully pass the UL94 V-0 flammability rating, the LOI value of EP-2 can reach $31.4 \%$, the impact strength and tensile strength was $6.58 \mathrm{~kJ} / \mathrm{m}^{2}$ and $47.10 \mathrm{MPa}$ respectively, and the adhesive strength was $13.79 \mathrm{MPa}$, the system presents a good overall performance.
\end{abstract}

Keywords: flame retardant; curing agent; synthesis; epoxy resin; property

\section{Introduction}

Epoxy resin has excellent mechanical properties, electrical properties, bonding properties and so on. So many advantages make it widely used in the electrical

\footnotetext{
* Corresponding author: Pingli Mao, School of Material Science and Engineering, Shenyang University of Technology, Shenyang 110870, China,email:maopl@sut.edu.cn Anxin Li, School of Material Science and Engineering, Shenyang University of Technology, Shenyang 110870 , China

Bing Liang, School of Material Science and Engineering, Shenyang University of Chemical Technology, Shenyang 110142, China
}

and electronic, construction, chemicals, machinery, transportation, national defense construction, aerospace, optical instruments, sports equipment, and many other areas. In terms of its practical application, the epoxy resin is required to have better flame retardant properties, which have improved the development of the flame retardant epoxy resin (1-3).

Nowadays, the method of adding flame retardant by physical blending has still been widely used as its easy operation and low cost. Its flame retardant effects lessen rapidly as time passes by, especially in harsh environments, and because it is added as filler, it will have a certain impact on the mechanical properties of the material. Therefore, another method that incorporates flame retardant elements $(\mathrm{P}, \mathrm{N}, \mathrm{Si}, \mathrm{B}$, etc.) into polymer backbone or network chemical bonding is being extensively studied (4-7). Phosphorus-containing flame retardant curing agents, a part of reactive flame retardant, have drawn people's attention due to their advantages that they are halogenfree, low in toxicity and relatively efficient. There are many possibilities for phosphorus-containing chemical structures to be modified to adjust their different properties, such as ammonium polyphosphate (APP), 9,10-dihydro-9-oxa-10phosphaphenanthrene-10-oxide (DOPO), which are used as an intermediate in phosphorus-containing flame retardants. Many different flame retardants have been synthesized, most of which have good flame retardancy (8-11).

Phosphorus and nitrogen have been confirmed to have a synergistic effect during the burning process, which can improve the flame retardant effect (12-14). Thus a phosphorus nitrogen flame retardant curing agent was synthesized in this study, where the nitrogen in the form of amino groups is used as crosslinking groups, and a series of flame retardant epoxy resin systems were prepared. The flame retardancy of EP/PPXSPB thermosets was investigated by limiting oxygen index (LOI) and vertical burning test (UL94), the thermal degradation behavior was tested by thermal gravimetric analysis (TGA), and the mechanical properties were investigated by tensile strength and charpy impact strength tests and adhesive strength tests, respectively, and the scanning 
electron microscopy (SEM) was used to analysis the impact sections morphologies of EP/PPXSPB thermosets from impact tests and the char residues morphologies of the EP/PPXSPB thermosets.

\section{Experimental}

\subsection{Materials}

P-xylylenediamine (PXDA, chemically pure) were purchased from Shandong Xiya Chemical Reagent Co., Ltd. (Shandong, China), phosphorus oxychloride ( $\mathrm{POCl}_{3}$, analytical reagent (AR)), 4-dimethylaminopyridine (DMAP, AR), Pentaerythritol (PER, AR), acetonitrile (AR), chlorobenzene (AR), and dichloromethane $\left(\mathrm{CH}_{2} \mathrm{Cl}_{2}, \mathrm{AR}\right)$ were all purchased from Sinopharm Chemical Reagent Co., Ltd (Shanghai, China). The EP resin (bisphenol A diglycidyl ether, trade name E-44, EP equivalent = 210-240 g/eq) was purchased from Jinan Zhuopu Chemical Technology Co., Ltd (Jinan, China).

\subsection{Synthesis}

\subsubsection{Synthesis of the SPDPC (pentaerythritol diphosphate diphosphoryl chloride)}

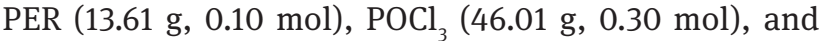
chlorobenzene $(150 \mathrm{~mL})$ were introduced into a $500 \mathrm{~mL}$, three-neck and round-bottom glass flask equipped with a condenser, a dry $\mathrm{N}_{2}$ inlet, a thermometer, a magnetic stirrer, and a gas absorber. DMAP (0.13 g, $0.0011 \mathrm{~mol})$ as catalyst was also added into the glass flask. The mixture was stirred at $60^{\circ} \mathrm{C}$ for $2 \mathrm{~h}$ and $80^{\circ} \mathrm{C}$ for $6 \mathrm{~h}$. Then mixture continued to react at $95^{\circ} \mathrm{C}$ until no large amount of $\mathrm{HCl}$ gas was spilled over. All reactions were carried out under dry $\mathrm{N}_{2}$ atmosphere. The crude product was washed with $\mathrm{CH}_{2} \mathrm{Cl}_{2}$ and ethanol sequentially, and then dried it at $80^{\circ} \mathrm{C}$ for $12 \mathrm{~h}$ under vacuum until its quality does not change. The obtained white solid powder was SPDPC. Yield: $26.34 \mathrm{~g}(88.9 \%)$. Scheme $1 \mathrm{a}$ is the reaction formula.

\subsubsection{Synthesis of the PPXSPB}

PXDA (57.20 g, $0.42 \mathrm{~mol})$ and acetonitrile (230 mL) were introduced into a $500 \mathrm{~mL}$ four-neck and round-bottom glass flask equipped with a magnetic stirrer, reflux condenser, thermometer, and dry nitrogen inlet. The mixture was heated to $60^{\circ} \mathrm{C}$ under $\mathrm{N}_{2}$ atmosphere and stirred until PXDA dissolved completely. Then SPDPC (59.18 g, $0.2 \mathrm{~mol}$ ) was added. The reaction was stirred under $60^{\circ} \mathrm{C}$ for $2 \mathrm{~h}$. Then the reaction continued at $75^{\circ} \mathrm{C}$ for $6 \mathrm{~h}$. The mixture was filtered hot to remove excessive PXDA and acetonitrile, the crude product was washed successively for 3 times with acetonitrile, and then vacuum-dried at $70^{\circ} \mathrm{C}$ for $12 \mathrm{~h}$, and PPXSPB was the obtained white powder. Yield: $86.3 \mathrm{~g}$ $(87.0 \%)$. Scheme $1 \mathrm{~b}$ is the reaction formula.

\subsection{Preparation of flame-retarded EP resin}

PXDA was used as a pure sample curing agent which was used to compare with the flame retardant curing agent PPXSPB. The curing process of all flame retardant epoxy resin composites was under the same conditions. The mass ratios of all components are listed in Table 1 . The mixture was stirred continuously by high speed disperser for $20 \mathrm{~min}$ at $90^{\circ} \mathrm{C}$. When the mixture was mixed well, degassed it under vacuum for $30 \mathrm{~min}$, then the mixture was poured into a preheated mold at $119^{\circ} \mathrm{C}$. The samples were cured for $2 \mathrm{~h}$ at $119^{\circ} \mathrm{C}, 3 \mathrm{~h}$ at $146^{\circ} \mathrm{C}$ and then postcured for $2 \mathrm{~h}$ at $178^{\circ} \mathrm{C}$.

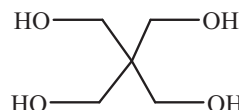<smiles>O=P(Cl)(Cl)Cl</smiles>

DMAP

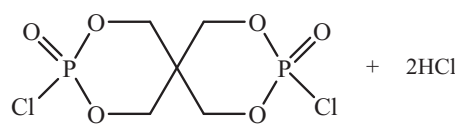

(a)
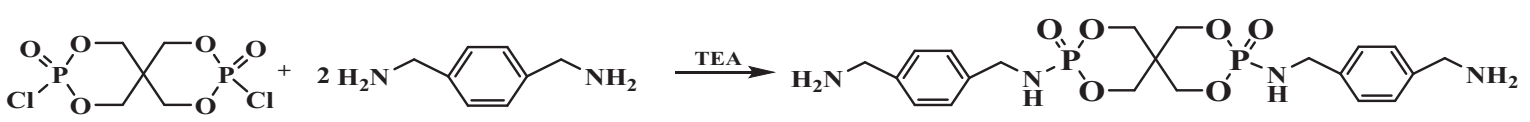

(b)

Scheme 1: Synthesis route of SPDPC (a) and PPXSPB (b). 
Table 1: EP/PPXSPB flame retardant systems.

\begin{tabular}{lcccc}
\hline Sample & E-44 (g) & PPXSPB (g) & PXDA (g) & P (\%) \\
\hline EP-0 & 100 & 0 & 25 & 0 \\
EP-1 & 100 & 30 & 0 & 2.77 \\
EP-2 & 100 & 35 & 0 & 3.12 \\
EP-3 & 100 & 40 & 0 & 3.42 \\
\hline
\end{tabular}

Note: The phosphorus content is calculated as: "P\% $=(P P X S P B$ mass / total mass of the system) $\times 12.01 \mathrm{wt} \% \times 100 \%$ ". (12\% is the mass fraction of $\mathrm{P}$ in the PMXSPB, and phosphorus content is determined by ammonium molybdate spectrophotometric method)

\subsection{Characterization}

Phosphorus content was determined by 721 digitally visible spectrophotometer (Sanghai Jinghua, China) according to the GB/T11893-89, potassium persulfate was used as the oxidant to digest the solid sample.

FTIR analysis was performed using a Thermo Nicolet NEXUS-470 (Ramsey, Minnesota, USA) spectrometer by an attenuated total reflectance method. Each sample was scanned from 4000 to $400 \mathrm{~cm}^{-1}$.

${ }^{1}$ HNMR spectra and ${ }^{31} \mathrm{PNMR}$ were recorded on an AVANCE III 500MHz spectrometer (Bruker, Switzerland). The chemical shifts relative to that of DMSO- $d_{6}$ were recorded.

The molecular weight was determined by micrOTOF-Q 125 (Bruker Customer, Germany), with the sample dissolved in methanol.

Thermogravimetric analysis (TGA) were performed on a STA449C/41G thermal analyzer (NETZSCH, Germany). The mass of PPXSPB was $5 \mathrm{mg}$, and EP-0, EP-1, EP-2, EP-3 were the same, $4.5 \mathrm{mg}$. Each sample was tested from 30 to $800^{\circ} \mathrm{C}$ at a heating rate of $10^{\circ} \mathrm{C} /$ min under $\mathrm{N}_{2}$ or air atmosphere.

The limiting oxygen index (LOI) is used to indicate the concentration (volume fraction) of oxygen in a mixture of oxygen and nitrogen when it is just capable of supporting its combustion. LOI test was carried out according to the GB/T2406-1993. The LOI was measured using a JF-3 LOI chamber (Jiangning Analytical Instrument Factory, Nanjing, China), and according to the ASTM D2863 standard, the sample dimensions were $130 \times 6.5 \times 3.0 \mathrm{~mm}^{3}$.

The vertical burning tests (UL94) were measured by a CZF-3 instrument (Jiangning Analytical Instrument Factory, Nanjing, China), and according to the ASTM D3801 testing procedure, the sample dimensions were $130 \times 13.0 \times 3.0 \mathrm{~mm}^{3}$. The vertical burning categories are shown in Table 2 according to EN 60695-11-10:1999.

For each set of five test specimens from the two conditional treatments, calculate the total afterflame time for the set $t_{\mathrm{f}}$ in seconds, using the following equation:
Table 2: Vertical burning categories.

\begin{tabular}{|c|c|c|c|}
\hline \multirow[t]{2}{*}{ Criteria } & \multicolumn{3}{|c|}{ Category (see note) } \\
\hline & V-0 & $V-1$ & $V-2$ \\
\hline $\begin{array}{l}\text { Individual test specimen afterflame time } \\
\left(t_{1} \text { and } t_{2}\right)\end{array}$ & $\leq 10 \mathrm{~s}$ & $\leq 30 \mathrm{~s}$ & $\leq 30 \mathrm{~s}$ \\
\hline $\begin{array}{l}\text { Total set afterflame time } t_{f} \text { for any } \\
\text { conditioning }\end{array}$ & $\leq 50 \mathrm{~s}$ & $\leq 250 \mathrm{~s}$ & $\leq 250 \mathrm{~s}$ \\
\hline $\begin{array}{l}\text { Individual test specimen afterflame } \\
\text { plus afterglow time after the second } \\
\text { application }\left(t_{2}+t_{3}\right)\end{array}$ & $\leq 30 \mathrm{~s}$ & $\leq 60 \mathrm{~s}$ & $\leq 60 \mathrm{~s}$ \\
\hline $\begin{array}{l}\text { Did the afterflame and/or afterglow } \\
\text { progress up to the holding clamp? }\end{array}$ & No & No & No \\
\hline $\begin{array}{l}\text { Was the cotton indicator pad ignited by } \\
\text { flaming particles or drops? }\end{array}$ & No & No & Yes \\
\hline
\end{tabular}

Note: If the test results are not in accordance with the specified criteria, the material cannot be categorized by this test method. Use the horizontal burning test method described in clause 8 to categorize the burning behavior of material.

$$
t_{f}=\sum_{i=1}^{5}\left(t_{1, i}+t_{2, i}\right)
$$

where:

$\mathrm{t}_{\mathrm{f}}$ - the total afterflame time, in seconds;

$t_{1, i}-$ the first afterflame, in seconds, of the $i^{\text {th }}$ test specimen;

$t_{2, i}$ - the second afterflame, in seconds, of the $i^{\text {th }}$ test specimen.

The standard sample for LOI and vertical burning was dried to constant weight at $70^{\circ} \mathrm{C}$, weighed and recorded as $\mathrm{W}_{0}$; it was placed in distilled water at $70^{\circ} \mathrm{C}$ for $168 \mathrm{~h}$, and dried it at $70^{\circ} \mathrm{C}$ to constant weight, recorded as $\mathrm{W}_{1}$. The immersed samples were subjected to LOI and vertical burning tests. The mobility of the flame retardant in EP/PPXSPB flame retardant systems is calculated according to the formula:

$$
\mathrm{M} \%=\frac{W_{0}-W_{1}}{W_{0}} \times 100 \%
$$

Cone calorimeter test was carried out according to the ISO 5660-1 standard on a FTT cone calorimeter (Fire Testing Technology Co. Ltd. UK). Specimens with sheet dimensions of $100 \times 100 \times 3.0 \mathrm{~mm}^{3}$ were irradiated at a heat flux of $35 \mathrm{~kW} / \mathrm{m}^{2}$. Each sample was tested at least twice.

The tensile strength tests were performed according to the International Organization for Standardization ISO 527-2 standards using a TCS-2000 electric tensile tester (Gotech testing machines Inc., Taiwan), and the tests were performed at a speed of $10 \mathrm{~mm} \cdot \mathrm{min}^{-1}$ at room temperature. 
Charpy impact tests were performed according to ISO 179-1 standard using a GT-7045-MDL Charpy impact tester (Taiwan). All of the listed results are the mean of five samples. The dumbbell sample dimension of tensile tests was $200 \mathrm{~mm} \times 20 \mathrm{~mm} \times 4 \mathrm{~mm}$, and the size of the stretched part is $60 \mathrm{~mm} \times 10 \mathrm{~mm} \times 4 \mathrm{~mm}$. The sample dimension of charpy impact tests was $80 \mathrm{~mm} \times 10 \mathrm{~mm} \times 4 \mathrm{~mm}$.

Scanning electron microscopy (SEM) testing by an S-3400N instrument (Hitachi, Japan) was used to investigate the combustion residues of burned samples from cone calorimeter tests.

The adhesive strength tests were performed according to GB/T 7124-2008 using electronic universal testing machine RGD-5 (Shenzhen, China). The stretching rate was $10 \mathrm{~mm} / \mathrm{min}$, Iron substrate $100 \mathrm{~mm} \times 25 \mathrm{~mm} \times 5 \mathrm{~mm}$, sizing area of $12.5 \mathrm{~mm} \times 25 \mathrm{~mm}$, curing conditions of $119^{\circ} \mathrm{C} / 2 \mathrm{~h}+146^{\circ} \mathrm{C} / 2 \mathrm{~h}+178^{\circ} \mathrm{C} / 2 \mathrm{~h}$. The data was taken as the mean of five samples.

\section{Results and discussion}

\subsection{Structural characterization}

The structure of PPXSPB was characterized by FTIR, ${ }^{1} \mathrm{HNMR}$, and mass spectroscopy. Figure 1 was the FTIR spectra of SPDPC and PPXSPB, as is shown in spectra of PPXSPB, the absorption peak of $\mathrm{P}=0$ appears at $1245 \mathrm{~cm}^{-1}$, $1022 \mathrm{~cm}^{-1}$ and $1074 \mathrm{~cm}^{-1}$ are the absorption peaks of $\mathrm{P}-\mathrm{O}-\mathrm{C}$ and $\mathrm{P}-\mathrm{N}$ (15), respectively. Compared with SPDPC, the spectrum of PPXSPB shows the absorption peaks at $3380 \mathrm{~cm}^{-1}$ is attributed to the stretching vibration absorptions of $-\mathrm{NH}_{2}$. The absorption peak at $838 \mathrm{~cm}^{-1}$

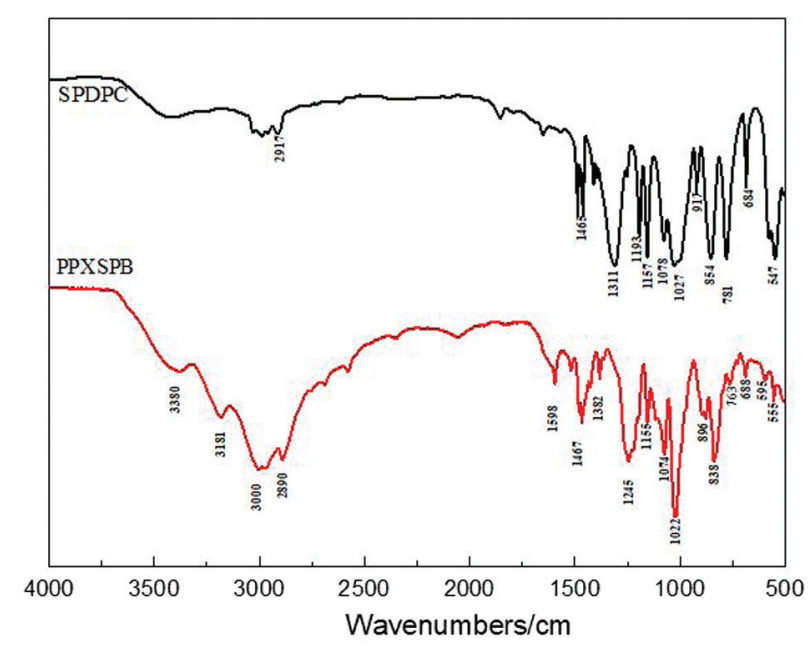

Figure 1: FTIR spectra of SPDPC and PPXSPB. is attributed to the bending vibration absorptions of $-\mathrm{Ph}$. The absorption peaks at $1598 \mathrm{~cm}^{-1}$ is assigned to the variable angle vibration of $-\mathrm{NH}(16)$, and the absorption peak of $\mathrm{P}=\mathrm{Cl}$ at $547 \mathrm{~cm}^{-1}$ disappeared.

Figure 2 was the ${ }^{1} \mathrm{HNMR}$ (a) and ${ }^{31} \mathrm{PNMR}$ (c) spectra of PPXSPB and the ${ }^{31}$ PNMR (b) spectrum of SPDPC. As is

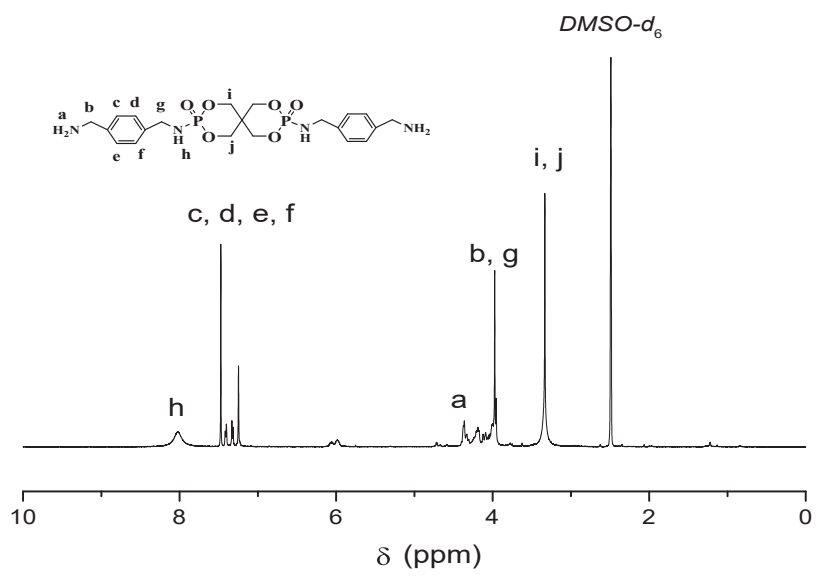

(a)

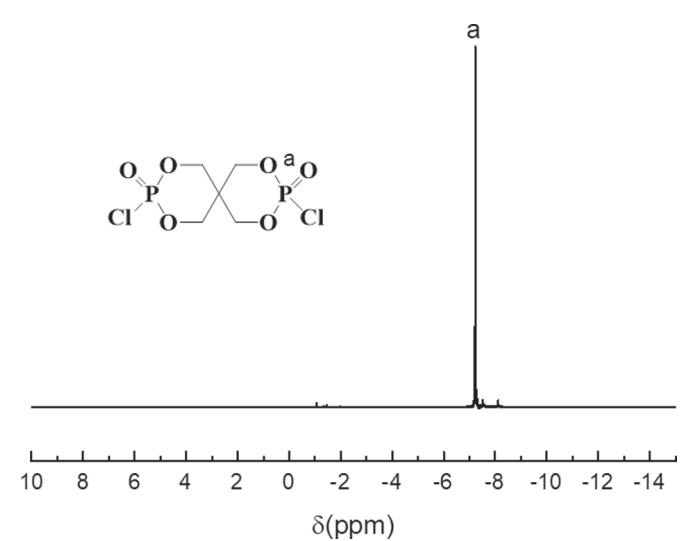

(b)

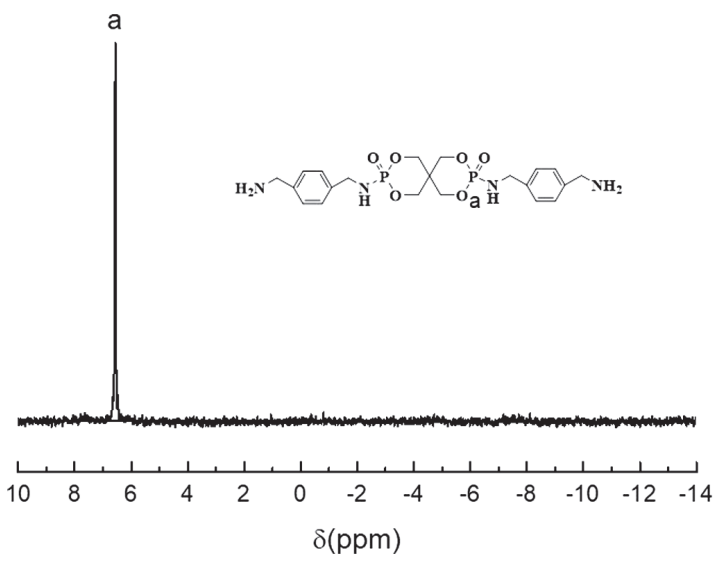

(c)

Figure 2: ${ }^{1} \mathrm{HNMR}(\mathrm{a})$ and ${ }^{31}$ PNMR (c) spectra of PPXSPB and ${ }^{31}$ PNMR (b) spectra of SPDPC. 


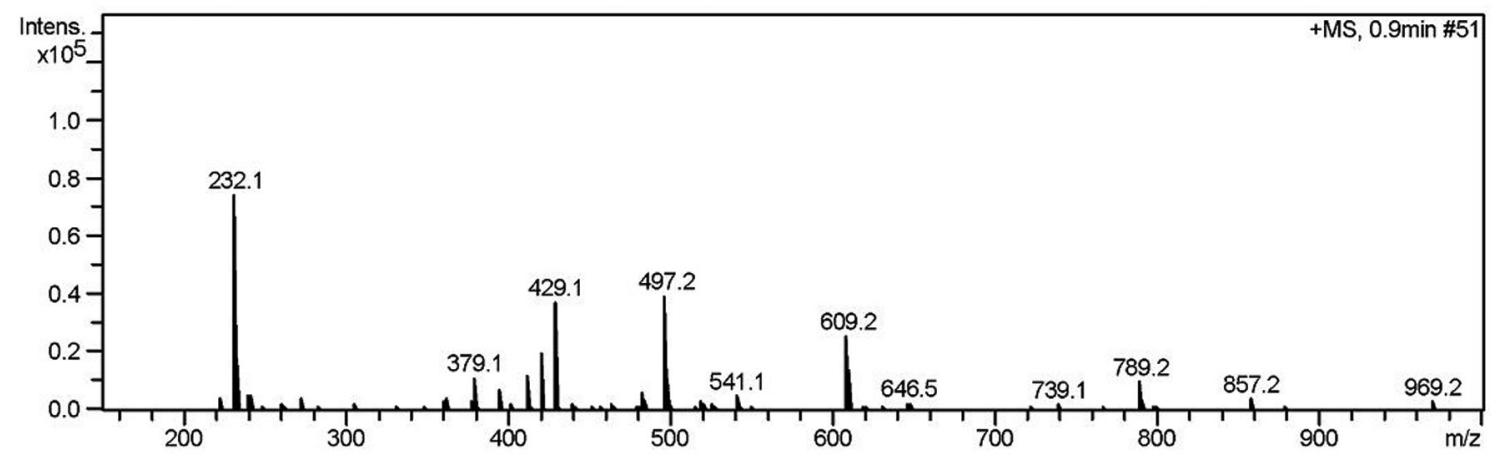

Figure 3: Mass spectrum of PPXSPB.

shown in Figure 2a, the signal at $2.50 \mathrm{ppm}$ is attributed to the DMSO- $d_{6}$ protons. The chemical shift of protons (b), (g) of methylene between $-\mathrm{NH}_{2}$ and the aromatic ring is at $3.9 \mathrm{ppm}$, and methylene proton adjacent to $\mathrm{P}-\mathrm{O}$ can be observed at $3.34 \mathrm{ppm}$. The chemical shifts of $-\mathrm{NH}_{2}$ adjacent to the aromatic ring is at $4.22 \mathrm{ppm}$, the chemical shifts of the protons (c), (d), (e) and (f) of the aromatic ring were observed at 7.15-7.56 $\mathrm{ppm}$. The protons $(\mathrm{h})$ of $-\mathrm{NH}$ between $-\mathrm{P}=\mathrm{O}$ and the aromatic ring is shown at $8.07 \mathrm{ppm}$. The ${ }^{31} \mathrm{PNMR}$ is shown in Figure 2c, the signal at $6.45 \mathrm{ppm}$ is attributed to the $\mathrm{P}$ proton, compared with Figure 2b, the signal at $6.45 \mathrm{ppm}$ disappeared, which proves that SPDPC has completely reacted.

The mass spectrum of PPXSPB is shown in Figure 3. The $\mathrm{m} / \mathrm{z}$ values $232.1,429.1,497.2,609.1,789.2$ are correspond to $1 / 13 \mathrm{M}_{8} \mathrm{H}^{+}, 1 / 2 \mathrm{M}_{2} \mathrm{H}^{+}, \mathrm{MH}^{+}, 1 / 2 \mathrm{M}_{3} \mathrm{H}^{+}$, $1 / 2 \mathrm{M}_{4} \mathrm{H}^{+}$, respectively, while $\mathrm{M}$ is the repeating unit of PPXSPB.

\subsection{Thermal stability of PPXSPB and EP/PPXSPB composite}

Figure $4 \mathrm{a}$ is the TG and DTG curves of PPXSPB in air atmosphere. Epoxy resin will decompose at about $200^{\circ} \mathrm{C}$ in air (17), while PPXSPB starts to decompose at $250 \sim 300^{\circ} \mathrm{C}$, which proves that it can adapt to the processing temperature of epoxy resin and may delay the decomposition of epoxy resin to some extent. The residual carbon content is $56.5 \%$ at $600^{\circ} \mathrm{C}$, this indicates that it has good char formation, which may have potential promotion effect on the flame retardancy of the material (18-21).

In order to study the thermal properties of the material degradation process, the thermal decomposition (TGA under nitrogen) and thermo-oxidate decompositon (TGA under air) of EP/PPXSPB composited are investigated.
The TG and DTG curves of EP/PPXSPB composited with different contents of PPXSPB in nitrogen and in air are shown in Figures $4 \mathrm{~b}$ and $4 \mathrm{c}$. It can be seen that the initial decomposition temperature of the EP/PPXSPB system is slightly lower than that of the pure epoxy resin in the atmosphere of both air and nitrogen. This is perhaps due to the larger steric hindrance of PPXSPB which leads to low crosslink density of the EP/PPXSPB systems $(22,23)$. As is shown in Figures $4 \mathrm{~b}$ and $4 \mathrm{c}$, the char yields around $480^{\circ} \mathrm{C}$ under air atmosphere are higher than which under nitrogen atmosphere. However, at $600^{\circ} \mathrm{C}$ and $800^{\circ} \mathrm{C}$, the result is reversed where the char yield is lower in $\mathrm{N}_{2}$ atmosphere. So we can infer that an oxidative environment promotes the formation of a char layer earlier, it helps the substrate to fully oxidize and degrade at high temperatures.

However, it is noted that the residual carbon yield of the cured epoxy resin increases as phosphorus increases. The residual char yield of EP-1, EP-2, and EP-3 are 23\%, $25 \%$, and $27 \%$ respectively, while the residual char yield of EP-0 is only 5\%. It means that the PPXSPB can improve the carbonization characteristics of the epoxy resin during combustion. As a result, it can be concluded that the phosphorus and nitrogen in the EP/PPXSPB system have a synergistic effect in the condensed phase to promote charring of epoxy resin $(24,25)$.

\subsection{Water resistance and flame resistance of EP/PPXSPB composite}

The flame retardant and water resistance of the cured epoxy resins are listed in Table 3. As shown in Table 4, the LOI value of pure EP is only $18.0 \%$, with the increase of phosphorus content, the LOI value of EP-1, EP-2 and EP-3 are increased to 28.8\%, 31.4\%, and $32.2 \%$, respectively, which is due to the overall flame retardancy of the N-P synergistic flame retardant system $(26,27)$. After immersion in water at $70^{\circ} \mathrm{C}$ for $168 \mathrm{~h}$, the 


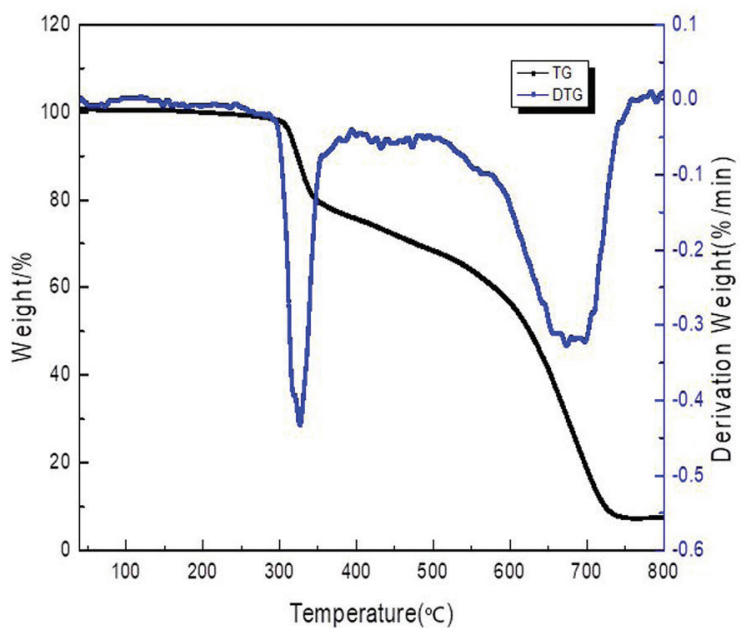

(a)
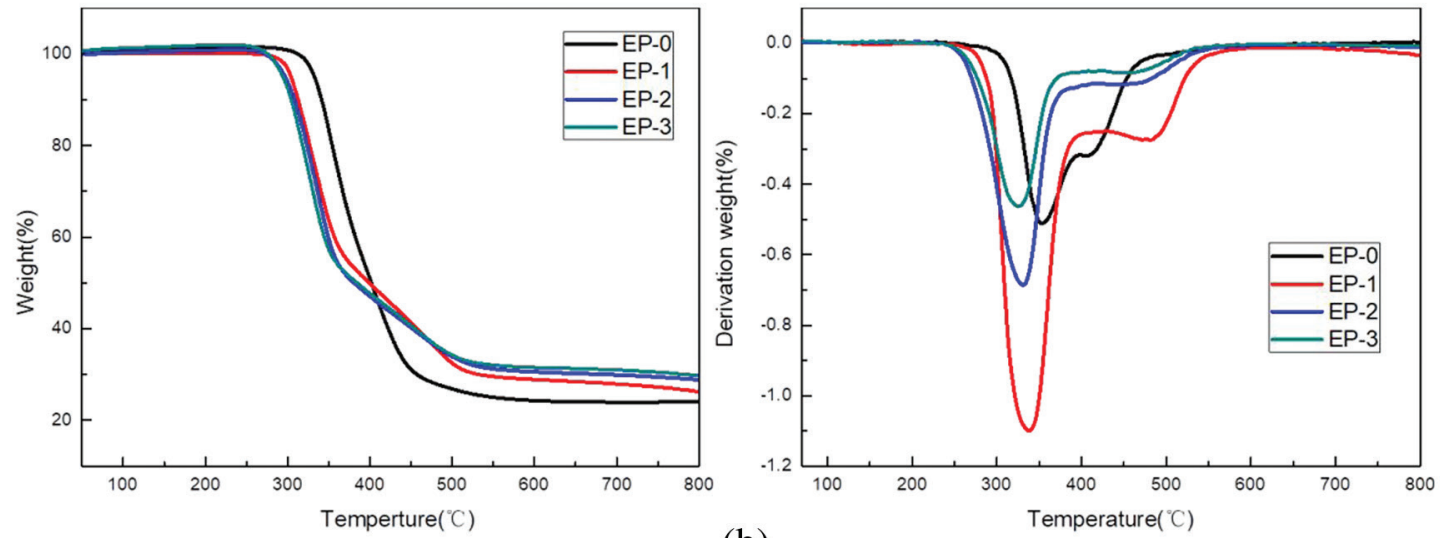

(b)
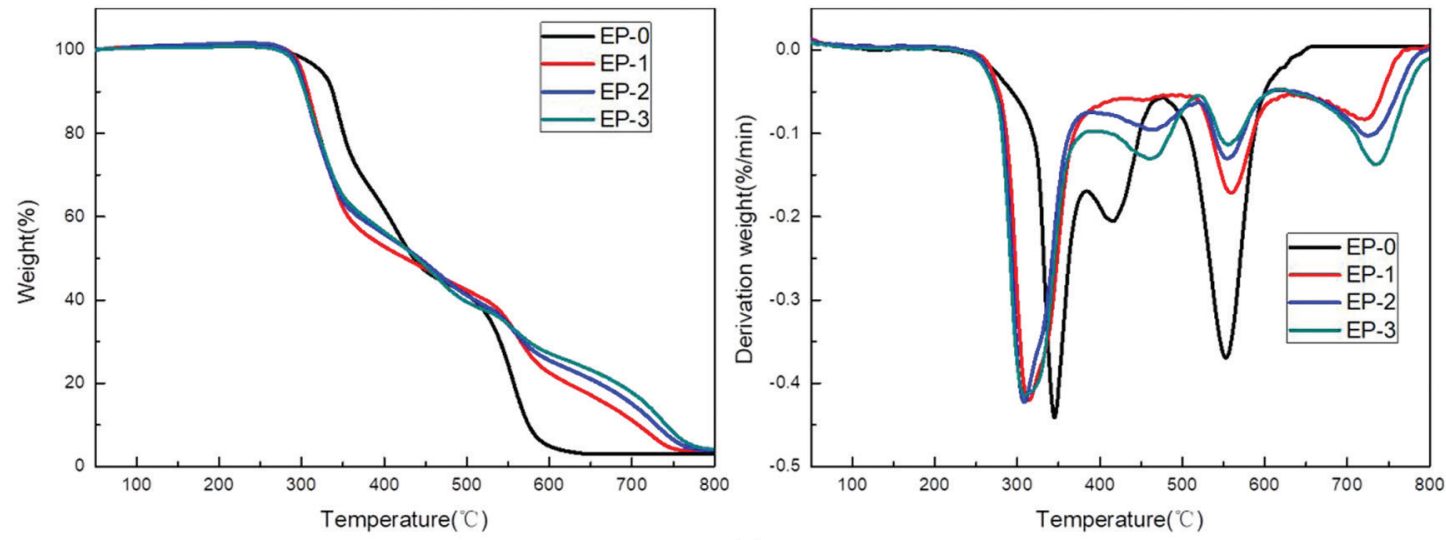

(c)

Figure 4: The TG and DTG curves of PPXSPB (a) and EP/PPXSPB composites (b,c): (a) in air atmosphere, (b) in nitrogen atmosphere, (c) in air atmosphere.

system shows a lower flame retardant migration rate. This is mainly due to the fact that PPXSPB forms a large number of chemical bond connections with epoxy, and the compatibility is greatly improved, thereby preventing the migration of the flame retardant to the surface of the material.

\subsection{The cone calorimeter test}

The fire hazard of materials is essentially a combination of thermal hazard and the smoke hazard. Therefore, it is necessary to analyze the combustion characteristics of materials that cause thermal hazards and smoke hazards 
under fire conditions. Using the cone calorimeter is an effective way to measure these indicators. The heat release rate (HRR) is one of the most important effective evaluation parameters for thermal hazards in fire behavior, and the smoke produce rate (SPR) reflects the smoke hazard when the material is burning.

As is shown in Figures 5a-c, the peak heat release rate (PHRR), total heat release (THR) and smoke produce

Table 3: Thermal analysis data of PPXSPB and EP/PPXSPB composites.

\begin{tabular}{|c|c|c|c|c|c|c|c|c|}
\hline \multirow[t]{2}{*}{ Samples } & \multicolumn{4}{|c|}{ Temperature of weight loss $\left({ }^{\circ} \mathrm{C}\right)$} & \multicolumn{4}{|c|}{ Residue (\%) } \\
\hline & $\begin{array}{l}T_{5 \%} \\
\left(N_{2}\right)\end{array}$ & $\begin{array}{l}T_{5 \%} \\
\text { (Air) }\end{array}$ & $\begin{array}{l}T_{\max } \\
\left(N_{2}\right)\end{array}$ & $\begin{array}{l}\mathrm{T}_{\max } \\
\text { (Air) }\end{array}$ & $\begin{array}{c}600^{\circ} \mathrm{C} \\
\left(\mathrm{N}_{2}\right)\end{array}$ & $\begin{array}{c}600^{\circ} \mathrm{C} \\
\text { (Air) }\end{array}$ & $\begin{array}{c}800^{\circ} \mathrm{C} \\
\left(\mathrm{N}_{2}\right)\end{array}$ & $\begin{array}{c}800^{\circ} \mathrm{C} \\
\text { (Air) }\end{array}$ \\
\hline PPXSPB & / & 290 & / & 320 & / & 59.1 & / & 9 \\
\hline EP-0 & 330 & 317 & 353 & 345 & 24.4 & 4.9 & 24.2 & 0.2 \\
\hline EP-1 & 295 & 300 & 326 & 314 & 28.8 & 22.5 & 26.0 & 1.5 \\
\hline EP-2 & 292 & 297 & 329 & 309 & 30.7 & 25.5 & 28.9 & 2.1 \\
\hline EP-3 & 292 & 295 & 321 & 307 & 31.0 & 27.2 & 29.2 & 2.8 \\
\hline
\end{tabular}

Table 4: Flame retardance and water resistance of different simples.

\begin{tabular}{|c|c|c|c|c|c|c|c|c|c|c|c|}
\hline Sample & $t_{1}(s)$ & $t_{2}(s)$ & UL94 & LOI\% & Dripping & $\mathbf{M} \%$ & $t_{1}{ }^{\prime}(s)$ & $t_{2}^{\prime}(s)$ & $\begin{array}{c}\text { UL94 } \\
\text { (after water } \\
\text { immersion) }\end{array}$ & $\begin{array}{c}\text { LOI\% } \\
\text { (after water } \\
\text { immersion) }\end{array}$ & $\begin{array}{c}\text { Dripping } \\
\text { (after water } \\
\text { immersion) }\end{array}$ \\
\hline EP-O & 45 & 39 & Burning & 18.0 & No & 0.02 & 49 & 39 & Burning & 18 & No \\
\hline EP-1 & 9 & 8 & V-0 & 28.8 & No & 0.11 & 20 & 12 & V-1 & 28.0 & No \\
\hline EP-2 & 7 & 5 & $\mathrm{~V}-0$ & 31.4 & No & 0.18 & 9 & 7 & $\mathrm{~V}-0$ & 30.5 & No \\
\hline EP-3 & 7 & 4 & V-0 & 32.2 & No & 0.27 & 9 & 4 & V-0 & 31.0 & No \\
\hline
\end{tabular}

(a)

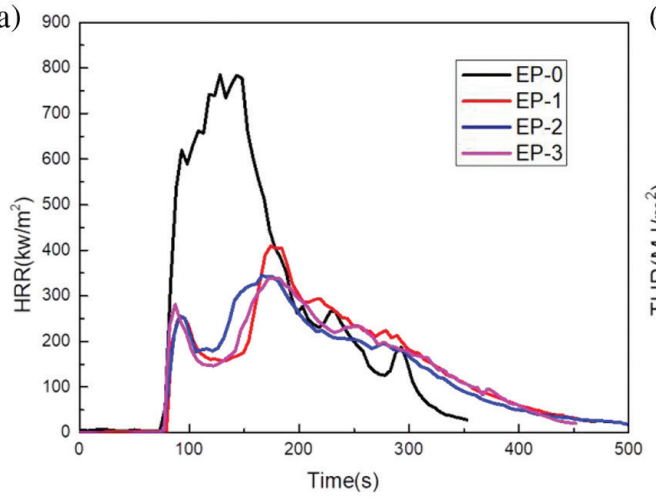

(b)

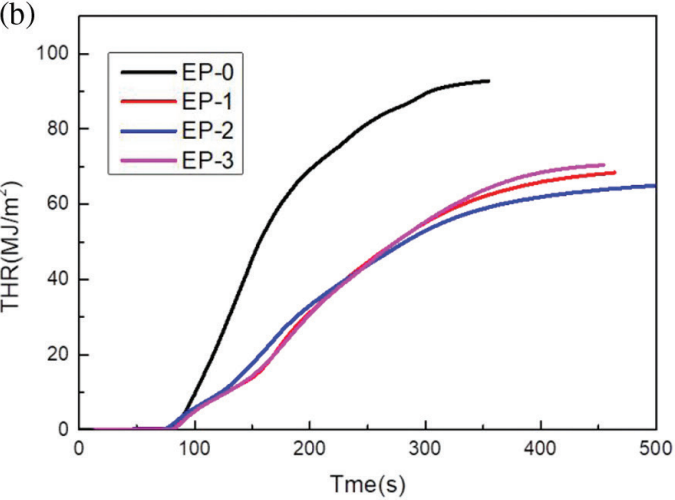

(c)

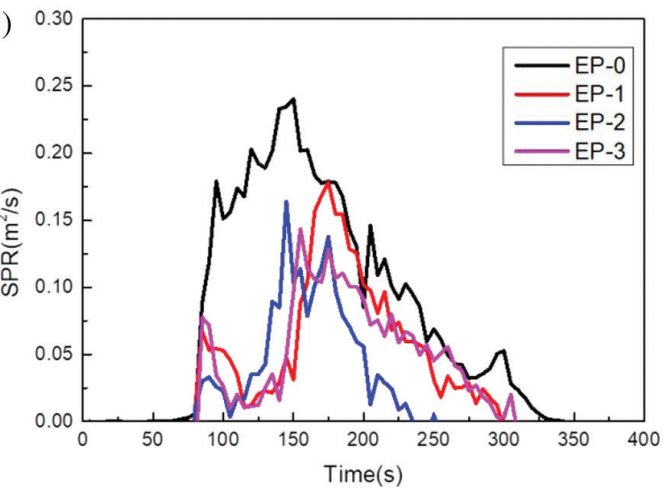

Figure 5: HRR (a), THR (b), and SPR (c) curves of EP/PPXSPB composites. 
rate (SPR) of EP/PPXSPB composites are all lower than that of EP-0. This means that it can provide longer time for human escapes in the event of a fire. From the trend of HRR curve we can infer that after the flame retardant system begins to burn, the surface of the system rapidly forms a layer of carbon under the catalysis of the produced phosphoric acid, thereby causing a small decrease of HRR at the beginning of combustion.

SEM and digital images of the char residues after cone calorimeter test are revealed in Figure 6, combined with the residue which is showed in Table 5 , it is obvious that after burning, EP-0 has only a small amount of residue, while the char of EP-2 was fully expanded and covered with small bubbles containing non-combustible gas. The surface of the system is heated to form an expanded carbon layer. On the one hand, external radiant heat is difficult to transfer to the inside, reducing the heat absorption value of the internal material and reducing the pyrolysis rate (28). On the other hand, it increases the time required for thermal degradation to release flammable volatiles. At the same time, the non-combustible gas released by the ruptured bubbles, such as $\mathrm{NH}_{3}, \mathrm{H}_{2} \mathrm{O}$, etc., takes away the heat required for combustion, and the carbon layer formed on the surface can retard the contact speed of the material interior with oxygen to some extent, thereby delaying the burning of the materials (29).

\subsection{Tensile strength, impact strength and adhesive strength of EP/PPXSPB composite}

The tensile strength, impact strength and adhesive strength properties of different simples are shown in Table 6. The tensile strength and impact strength properties of EP/PPXSPB composite are reduced than EP-0. On the one hand, compared with the liquid curing agent used in EP-0, the solid curing agent used in this EP/PPXSPB composite
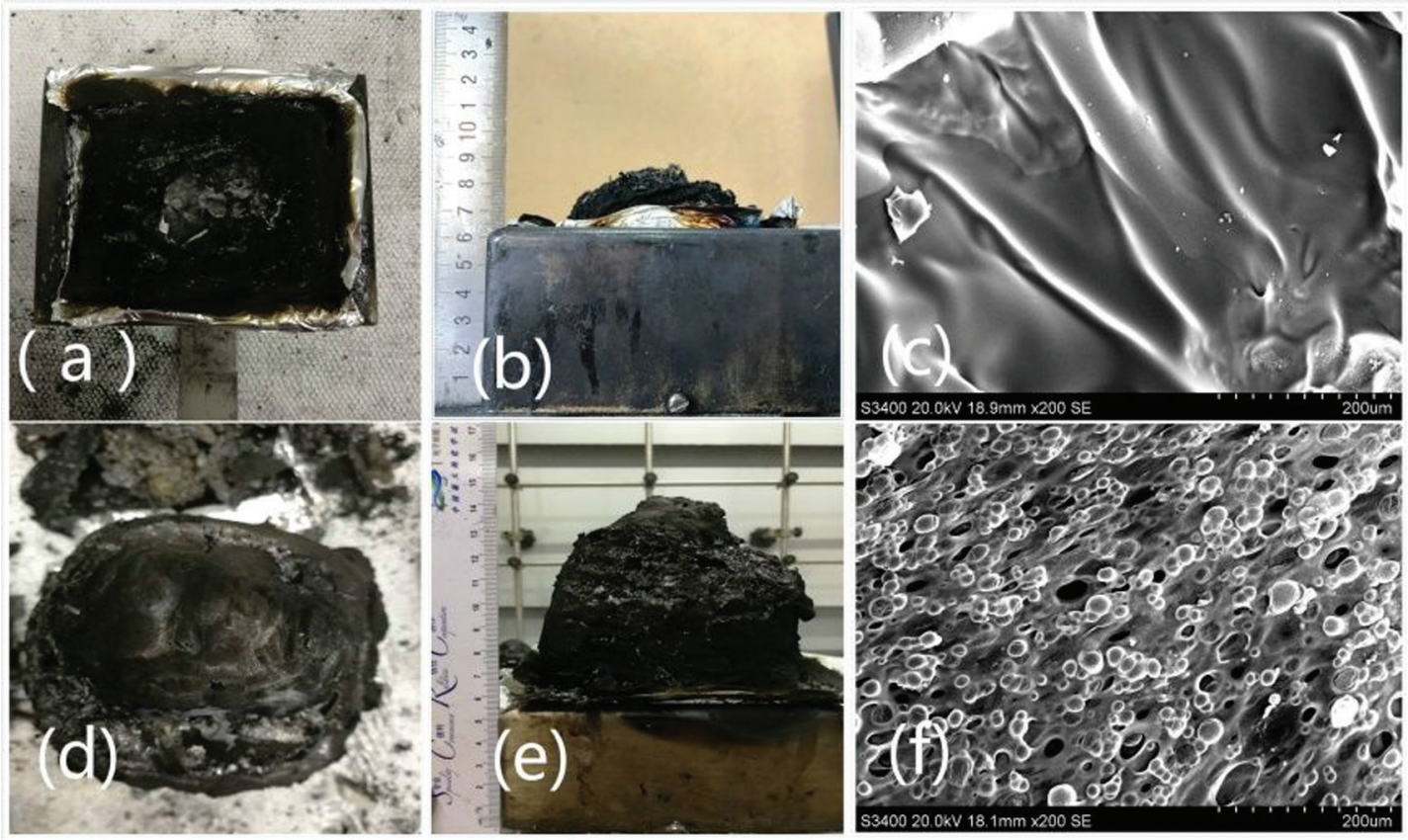

Figure 6: SEM and digital images of the char residues after cone calorimeter test: (a) EP-0, (b) EP-0, (c) EP-0 magnification: $200 \times$, (d) EP-2, (e) EP-2, (f) EP-2 magnification: $200 \times$.

Table 5: Cone calorimeter data of EP/PPXSPB composites.

\begin{tabular}{|c|c|c|c|c|c|c|c|c|}
\hline Samples & $\begin{array}{l}\text { TTI } \\
\text { (s) }\end{array}$ & $\begin{array}{c}\text { PHRR } \\
\left(\mathrm{kW} / \mathrm{m}^{2}\right)\end{array}$ & $\begin{array}{c}\text { avHRR } \\
\left(\mathrm{kW} / \mathrm{m}^{2}\right)\end{array}$ & $\begin{array}{c}\text { THR } \\
\left(\mathrm{MJ} / \mathrm{m}^{2}\right)\end{array}$ & $\begin{array}{c}\text { avEHC } \\
(\mathrm{MJ} / \mathrm{kg})\end{array}$ & $\begin{array}{c}\text { avMLR } \\
(\mathrm{g} / \mathrm{s})\end{array}$ & $\begin{array}{c}\text { TSR } \\
\left(\mathrm{m}^{2} / \mathrm{m}^{2}\right)\end{array}$ & $\begin{array}{c}\text { Residue } \\
\text { (\%) }\end{array}$ \\
\hline EP-0 & 79 & 785.54 & 335.44 & 92.25 & 23.20 & 0.128 & 3216.37 & 10.27 \\
\hline EP-1 & 80 & 409.57 & 176.07 & 68.27 & 16.85 & 0.092 & 3003.04 & 25.83 \\
\hline EP-2 & 81 & 344.52 & 146.06 & 65.00 & 16.29 & 0.075 & 2746.96 & 32.34 \\
\hline EP-3 & 81 & 339.80 & 145.50 & 63.40 & 16.06 & 0.067 & 2549.81 & 32.50 \\
\hline
\end{tabular}


Table 6: Tensile strength, impact strength and adhesive strength of EP/PPXSPB composite.

\begin{tabular}{lcccc}
\hline Sample & $\mathbf{P} \%$ & $\begin{array}{c}\text { Tensile strength } \\
(\mathbf{M P a})\end{array}$ & $\begin{array}{c}\text { Impact strength } \\
\left.(\mathbf{k}) / \mathbf{m}^{2}\right)\end{array}$ & $\begin{array}{c}\text { Adhesive } \\
\text { strength }(\mathbf{M P a})\end{array}$ \\
\hline EP-0 & 0 & $64.97 \pm 0.97$ & $7.11 \pm 0.91$ & $13.0 \pm 0.69$ \\
EP-1 & 2.88 & $35.21 \pm 0.87$ & $4.86 \pm 0.45$ & $11.62 \pm 0.34$ \\
EP-2 & 3.24 & $47.10 \pm 0.71$ & $6.58 \pm 0.68$ & $13.79 \pm 0.65$ \\
EP-3 & 3.56 & $40.21 \pm 0.99$ & $5.92 \pm 0.72$ & $12.88 \pm 0.59$ \\
\hline
\end{tabular}

is less likely to be evenly dispersed. During the mixing of the flame retardant system, some of the PPXSPB did not uniformly disperse, resulting in a slight agglomeration phenomenon, so that some PPXSPB cannot bond well with the epoxy resin and cause a slight gap in the system (30). Eventually, if there is external force contact, the system is unevenly stressed, and it is more prone to brittle fracture. On the other hand, steric hindrance is also one of the causes of the deterioration of the mechanical properties of the material. Larger steric hindrance of PPXSPB reduces the reactivity of PPXSPB, and some unreacted PPXSPB acts as a filler, thereby reducing the crosslink density of the system.

As for the adhesive strength of different simples, the adhesive strength of EP-2 increase 6\% than that of EP-0. The main reason for this phenomenon is that the two curing agents have different internal stresses in the curing process. It is known that the use of a liquid curing agent will cause a certain degree of volume shrinkage of the curing system. When the internal stress is large, the adhesive strength will be significantly reduced. In addition, the stress distribution around the adhesive end or adhesive gap is not uniform, the resultant stress also increased the possibility of cracks appear. While PPXSPB is a solid curing agent, PPXSPB can partially act as filler during curing process, so the volume shrinkage of the cured product was reduced (31). At the same time, when the cured material containing the filler subject to the stress, the stress will be uniformly transferred to the surface of the filler particles. The filler takes most of the stress and played a role in the uniform distribution of stress. So there is a higher adhesive strength. However, too much excessive PPXSPB is equivalent to add an excessive amount of filler into the system. Excessive filler will reduce the degree of crosslinking of the system, and result in a decrease in adhesive strength.

\section{Conclusions}

A phosphorus-nitrogen flame-retardant curing agent PPXSPB was successfully synthesized. The impact of
PPXSPB on the properties of the epoxy resin (E-44) was discussed. The results show that with the increase of phosphorus content, the flame retardant effect of the system is getting better and better. As a reactive flame retardant curing agent, it has excellent water resistance and is difficult to migrate. When the phosphorus content is $3.24 \%$, the comprehensive performance of the system is best. The LOI value is $31.4 \%$, impact strength is $6.58 \mathrm{~kJ} / \mathrm{m}^{2}$, tensile strength is $47.10 \mathrm{MPa}$ and the adhesive strength is 13.79 MPa.

Declaration of conflicting interests: Authors declared no potential conflicts of interest with respect to the research, authorship, and/or publication of this article.

Acknowledgements: Authors would like to acknowledge the financial support from Shenyang Science and Technology plan 2017 project (17-9-6-00).

\section{References}

1. Zhang X., He Q., Gu H., Henry A.C., Wei S.Y., Guo Z.H., Flameretardant electrical conductive nanopolymers based on bisphenol F epoxy resin reinforced with nano polyanilines. ACS Appl. Mater. Interf., 2013, 5, 898-910.

2. Weil E., Levchik S., A review of current flame retardant systems for epoxy resins. J. Fire Sci., 2004, 22, 1-25.

3. Zhao W., Liu J., Peng H., Liao J.Y., Wang X.J., Synthesis of a PEPA-substituted polyphosphoramide with high char residues and its performance as an intumescent flame retardant for epoxy resins. Polym. Degrad. Stabil., 2015, 118, 120-129.

4. Xiao L., Sun D., Niu T., Yao Y.W., Syntheses and characterization of two 9,10-dihydro-9-oxa-10-phosphaphenanthrene-10-oxidebased flame retardants for epoxy resin. High Perform. Polym., 2014, 26, 52-59.

5. Deng J., Shi W.F., Synthesis and effect of hyperbranched (3-hydroxyphenly) phosphate as a curing agent on the thermal and combustion behaviors of novolac epoxy resin. Eur. Polym. J., 2004, 40, 1137-1143.

6. Kalali E.N., Wang X., Wang D.Y., Functionalized layered double hydroxide-based epoxy nanocomposites with improved flame retardancy and mechanical properties. J. Mater. Chem. A, 2015, 3, 6819-6826.

7. Xu G.R., Xu M.J., Li B., Synthesis and characterization of a epoxy resin based on cyclotriphosphazene and its thermal degradation and flammability performance. Polym. Degrad. Stabil., 2014, 109, 240-248.

8. Yuan Y., Yang H., Yu B., Shi Y.Q., Wang W., Song L., et al., Phosphorus and Nitrogen-Containing Polyols: Synergistic Effect on the Thermal Property and Flame Retardancy of Rigid 
Polyurethane Foam Composites. Ind. Eng. Chem. Res., 2016, 55, 10813-10822.

9. Li Z.S., Song T., Liu J.A., Yan Y., Thermal and combustion behavior of phosphorus-nitrogen and phosphorus-silicon retarded epoxy. Iran. Polym. J., 2017, 26, 21-30.

10. Lin Y., Sun J., Zhao Q., Zhou Q.Y., Synthesis and properties of a flame-retardant epoxy resin containing biphenylyl/phenyl phosphonic moieties. Polym. Plast. Technol. Eng., 2012, 51, 896-903.

11. Müller P., Schartel B., Melamine poly(metal phosphates) as flame retardant in epoxy resin: performance, modes of action and synergy. J. Appl. Polym. Sci., 2016, 133, 43549.

12. Toldy A., Anna P., Csontos I., Marosi G., Intrinsically flame retardant epoxy resin-Fire performance and background - Part I. Polym. Degrad. Stabil., 2007, 92, 2223-2230.

13. Ma H.Y., Li F.T., Xu Z.B., Fang Z.P., Jin Y.M., Lu F.Z., A noval intumescent flame retardant: Synthesis and application in ABS copolymer. Polym. Degrad. Stabil., 2007, 92, 720-726.

14. Wang Q., Chen Y.H., Liu Y., Wang Q., Yin H., Aelmans N., et al., Performance of intumescent flame retardant master batch synthesized through twin-screw reactively extruding technology: effect of component ratio. Polym. Int., 2004, 53, 439-448.

15. Yang X.J., Wang C.P., Xia J.L., Mao W., Li S.H., Study on synthesis of phosphorus-containing flame retardant epoxy curing agents from renewable resources and the comprehensive properties of their combined cured products. Prog. Org. Coat., 2017, 110, 195-203.

16. Li Q., Jiang P.K., Wei P., Synthesis characteristic and application of new flame retardant containing phosphorus nitrogen and silicon. Polym. Eng. Sci., 2006, 46, 344-350.

17. Qian X.D., Song L., Hu Y., Richard K.K.Y., Chen L.J., Guo Y.Q., et al., Combustion and Thermal Degradation Mechanism of a Intumescent Flame Retardant for Epoxy Acrylate Containing Phosphorus and Nitrogen. Ind. Eng. Chem. Res., 2011, 50, 1881-1892.

18. Ren R., Sun J.Z., Wu B.J., Zhou Q.Y., Synthesis and properties of aphosphorus-containing flame retardant epoxy resin based on bis-phenoxy (3-hydroxy) phenyl phosphine oxide. Polym. Degrad. Stabil., 2007, 92, 956-961.

19. Gao J.G., Li D.L., Shen S.G. Liu G.D., Curing kinetics and thermal property characterization of a bisphenol-F epoxy resin and DDO system. J. Appl. Polym. Sci., 2002, 83, 1586-1595.

20. Parveen K., Agarwal S., Naarual A.K., Choudhary V., Studies on the curing and thermal behavior of DGEBA in the presence of bis(4-carboxyphenyl) dimethyl silane. Polym. Int., 2003, 52, 908-917.

21. Frabcis B., Poel G.V., Posada F., Cure kinetics and morphology of composites of epoxy resin with poly (ether ether ketone) containing pendant tertiary butyl groups. Polymer, 2003, 44, 3687-3699.

22. Dong C.L., Wirasaputra A., Luo Q.Q., Liu S.M., Yuan Y.C., Zhou J.Q., et al., Intrinsic Flame-Retardant and Thermally Stable Epoxy Endowed by a Highly Efficient, Multifunctional Curing Agent. Materials, 2016, 9, 1-15.

23. Lu L.G., Qian X.D., Zeng Z.J., Yang S.S., Shao G.S., Wang H.Y., et al., phosphorus-based flame retardants containing 4-tert-butylcalix[4]arene: Preparation and application for the fire safety of epoxy resins. J. Appl. Polym. Sci., 2017, 134, 45105.

24. You Y.G., Cheng Z.Q., Peng H., He H.W., Synthesis and performance of a nitrogen-containing cyclic phosphate for intumescent flame retardant and its application in epoxy resin. J. Appl. Polym. Sci., 2015, 132, 41859.

25. Liang H.B., Ding J., Shi W.F., Kinetics and mechanism of thermal oxidative degradation of UV cured epoxy acrylate/ phosphate triacrylate blends. Polym. Degrad. Stabil., 2004, $86,217-223$.

26. Liu Z.Y., Xu M.J., Wang Q., Bin L., A durable flame retardant cotton fabric produced by surface chemical grafting of phosphorus- and nitrogencontaining compounds. Cellulose, 2017, 24, 4069-4081.

27. Liu H., Wang X.D., Wu D.Z., Synthesis of a linear polyphosphazene-based epoxy resin and its application in halogen-free flame-resistant thermosetting systems. Polym. Degrad. Stabil., 2015, 118, 45-58.

28. Luo Q.Q., Yuan Y.C., Dong C.L., Huang H.H., Liu S.M., Zhou J.Q., Highly Elective Flame Retardancy of a DPPA-Based Curing Agent for DGEBA Epoxy Resin. Ind. Eng. Chem. Res., 2016, 55, 10880-10888

29. You G.Y., Cheng Z.Q., Tang Y.Y., He H.W., Functional Group Effect on Char Formation, Flame Retardancy and Mechanical Properties of Phosphonate-Triazine-based Compound as Flame Retardant in Epoxy Resin. Ind. Eng. Chem. Res., 2015, 54, 7309-7319.

30. Liang B., Wang G., Hong X., Long J.P., Noritatsu T., Synthesis and properties of a new halogen-free flame-retardant epoxy resin curing agent. High Perform. Polym., 2016, 28, 110-118.

31. Liu X.L., Liang B., Impact of a phosphorus-nitrogen flame retardant curing agent on the properties of epoxy resin. Mater. Res. Express, 2017, 4, 125103. 